\title{
KERAGAMAN SERANGGA PENYERBUK PADA PERTANAMAN STRAWBERY YANG DISELINGI DENGAN TANAMAN Borreria laevicaulis
}

\author{
MARYAM MUJI LESTARI, IMAM WIDHIONO, EMING SUDIANA
}

Fakultas Biologi, Universitas Jenderal Soedirman, Jalan dr. Suparno 63 Purwokerto 53122

\section{A B S T R A C T}

The productivity of strawberry (Fragaria sp.) depends on the presence of pollinator insects that need nectar or pollen as their food. The diversity and the population size of pollinator insects can be increased by the companion planting of Borreria laevicaulis among the strawberry. This research aimed to determine the diversity of pollinator insects of strawberry plantation companion by B. laevicaulis and to determine the relationship between the diversity of pollinator insects with the strawberry fruit produced. This research was conducted in the strawberry plantation of Serang Village, of the District Karangreja, Purbalingga, from June to August 2012. The research was designed to determine the effect of companion planting of B. laevicaulis at the $0 \%, 5 \%, 10 \%$, and $15 \%$ of the total individuals of strawberry. The results showed that the companion planting of B. laevicaulis in the strawberry field did not affect the species diversity of pollinator insects. But the B. laevicaulis companion planting affected the amount of strawberry yielded. The maximum yield was obtained by planting $B$. laevicaulis at the $10 \%$ of the strawberry individuals; it was increased by $76.12 \%$ of the control without companion planting.

KEY WORDS: strawberry, pollinator insect, Borreria laevicaulis

Corresponding Author: IMAM WIDHIONO | email: imamwidhiono@yahoo.com

\section{PENDAHULUAN}

Strawberry (Fragaria sp.) merupakan tanaman yang memilki nilai ekonomis tinggi. Budidaya strawberry pertama kali dilakukan di negara yang beriklim subtropis. Seiring dengan perkembangan ilmu dan teknologi pertanian yang semakin maju pengembangan strawberry mendapat perhatian di negara yang beriklim tropis, termasuk Indonesia (Sastrapradja et al., 1980 dalam Erviana, 2011).

Strawberry memiliki bunga hermaprodit, yaitu memiliki satu pasang organ reproduktif (jantan dan betina) dalam satu bunga. Kematangan kedua organ reproduktif strawberry tersebut sangat berbeda. Organ reproduktif betina mengalami kematangan terlebih dahulu dibanding jantan (Roselino et al., 2009). Oleh karena itu fertilisasi strawberry tidak terjadi sendiri tetapi perlu dibantu oleh serangga penyerbuk. Keberhasilan proses penyerbukan sangat ditentukan oleh tingkat keragaman serangga penyerbuk. Semakin beragam serangga penyerbuk maka semakin tinggi keberhasilan penyerbukan.

Keragaman menunjukkan jumlah jenis serangga yang ada pada suatu habitat. Keragaman dan populasi serangga penyerbuk sangat bergantung pada mutu suatu habitat yaitu jumlah dan keragaman sumber pakan berupa tumbuhan berbunga dan ketersediaan bunga sepanjang tahun (Hodgson et al., 2011). Semakin beragam dan semakin banyak tumbuhan berbunga maka akan semakin tinggi keragaman serangga penyerbuk (Faheem et al., 2004). Faktor lain yang dapat mempengaruhi keragaman serangga penyerbuk adalah adanya sifat menarik dari bunga bagi suatu jenis serangga penyerbuk untuk berkunjung. Sifat menarik tersebut diantaranya adalah warna, bentuk, bau, serta ketersediaan nektar dan serbuk sari sebagai sumber pakan pada bunga (Abrol, 1992).

Peningkatan kelimpahan dan keragaman serangga penyerbuk pada tanaman strawberry dapat dilakukan dengan menambah jenis tumbuhan berbunga. Salah satu tumbuhan berbunga adalah Borreria laevicaulis, yang merupakan tumbuhan herba tahunan yang banyak ditemukan pada padang rumput, di bawah tegakan pinggir jalan terutama pada lahan tanah lembab dan teduh. Tinggi tanaman B. laevicaulis sekitar 30-50 cm dengan sistem percabangan batang yang menyebar ataupun tegak. Bentuk daunnya lonjong dengan panjang sekitar 2-4 cm. Bunganya berwarna putih dan memiliki pollen sebagai pemikat serangga untuk mau mengunjungi bunga dan sekaligus membantu penyerbukan bunga yang akan membentuk buah (Cardenas et al., 1972). Dengan demikian kelimpahan $B$. laevicaulis pada suatu lahan budidaya komoditas pertanian akan dapat meningkatkan keragaman serangga penyerbuk.

Hasil penelitian Widhiono et al. (2011) tentang hubungan antara keragaman tumbuhan berbunga dan serangga penyerbuk pada lahan pekarangan, lahan pertanian, dan habitat hutan tanaman di Gunung Slamet menunjukkan bahwa keragaman serangga penyerbuk tertinggi terdapat pada habitat hutan tanaman di Gunung Slamet dan terendah pada lahan pertanian. Perbedaan ini terjadi karena keragaman tanaman berbunga pada lahan pertanian lebih rendah dibandingkan yang lain. Berdasarkan hal tersebut maka penelitian ini bertujuan untuk; mengetahui keragaman serangga penyerbuk pada lahan tanaman strawberry yang diselingi dengan $B$. Laevicaulis dan mengetahui hubungan antara tingkat keragaman serangga penyerbuk dengan jumlah buah strawberry yang dihasilkan pada lahan tersebut. 


\section{MET O DE}

Penelitian ini dilaksanakan di pertanaman strawberry yang berlokasi di Desa Serang Kecamatan Karangreja Kabupaten Purbalingga, pada bulan Juni-Agustus 2012. Penelitian ini dilakukan dengan metode eksperimen dengan Rancangan Acak Lengkap. Perlakuan yang diterapkan berupa penanaman $B$. laevicaulis pada lahan tanaman strawberry dengan jumlah tanaman sebanyak $0 \%, 5 \%, 10 \%$, dan $15 \%$ dari jumlah populasi tanaman strawberry yang diteliti.

Variabel yang diamati adalah variabel bebas yaitu jumlah tumbuhan $B$. laevicaulis dan variabel bergantung yaitu keragaman serangga penyerbuk dan jumlah bunga strawberry yang diserbuki. Parameter yang diamati pada serangga meliputi jumlah jenis serangga, intensitas kunjungan serangga, dan lamanya serangga berkunjung pada bunga. Parameter yang diamati pada bunga meliputi jumlah bunga yang mekar dan jumlah bunga strawberry yang diserbuki. Tingkat keberhasilan proses penyerbukan dapat diukur berupa jumlah produksi buah. Parameter yang diukur meliputi jumlah jenis serangga penyerbuk, jumlah individu per spesies, dan jumlah buah strawberry yang dihasilkan pada saat panen pertama dalam setiap petak.

Penghitungan indeks keragaman jenis menggunakan indeks diversitas Shannon-Wienner mengacu pada Magurran (1988), yaitu:

$$
H=\sum_{i=1}^{s}(p i)(\ln p i)
$$

Keterangan:

$\mathrm{H}=$ indeks keragaman jenis

$\mathrm{S}=$ jumlah spesies

pi $=$ proporsi sampel total dihitung dari spesies ke- $i=1$

$\mathrm{pi}=\mathrm{ni} / \mathrm{N}$

$\mathrm{ni}=$ jumlah individu spesies ke- $i$

$\mathrm{N}=$ jumlah total individu yang tertangkap dari semua spesies

Data yang diperoleh dari jumlah dan jenis serangga penyerbuk serta tingkat keberhasilan penyerbukan dianalisis menggunakan ANOVA dilanjutkan dengan uji BNT pada tingkat kesalahan $1 \%$ dan $5 \%$. Analisis dilanjutkan dengan uji korelasi dan regresi. Analisis statistik tersebut dilakukan dengan menggunakan bantuan software SPSS.

\section{HASIL DAN PEMBAHASAN}

Serangga polinator yang didapat pada lahan tanaman strawberry yang diselingi dengan $B$. laevicaulis yaitu: Polistes tenebricosus yang termasuk familia Vespidae; Apis cerana, A. zonata, Cerratina sp. dari familia Apidae; Vanessa sp. dari familia Nymphalidae; dan Musca domestica dari familia Muscidae (Tabel 1). Familia Vespidae dan Apidae merupakan anggota dari ordo Hymenoptera, sedangkan familia Nymphalidae dari ordo Lepidoptera, dan familia Muscidae adalah anggota ordo Diptera. Spesies dari ordo Hymenoptera adalah yang paling banyak dietemukan pada lahan penelitian. Keenam spesies tersebut ditemukan pada setiap lokasi perlakuan. Hasil pengamatan terhadap jenis serangga penyerbuk, Vanessa sp. ditemukan dalam jumlah paling besar yaitu 45 individu, sedangkan Amegilla zonata adalah spesies yang ditemukan paling sedikit dengan jumlah 18 ekor (Tabel 1 dan Gambar 1).

Hasil analisis keanekaragaman serangga polinator ditentukan oleh nilai indeks Shannon-Wienner. Berdasarkan Tabel 2 serangga penyerbuk pada budidaya strawberry kontrol tanpa penanaman $B$. laevicaulis $(0 \%)$ memiliki nilai indeks $H^{\prime}=1,562$ sedangkan pada perlakuan B. laevicaulis sebanyak $5 \%$, $10 \%$, dan $15 \%$ memiliki nilai indeks $H^{\prime}$ berturut-turut 1,7447; 1,6939; dan 1,7317. Nilai indeks ShannonWienner pada perlakuan B. laevicaulis $5 \%$ lebih besar dibandingkan dengan nilai indeks pada perlakuan $10 \%$ dan $15 \%$.

Tabel 1. Spesies dan jumlah individu serangga penyerbuk yang terdapat pada lahan strawberry yang diselingi tanaman Borreria laevicaulis di Desa Serang Kecamatan Karangreja Kabupaten Purbalingga

\begin{tabular}{|c|c|c|c|c|c|c|}
\hline \multicolumn{2}{|c|}{ Serangga penyerbuk } & \multicolumn{4}{|c|}{$\begin{array}{l}\text { Jumlah individu } \\
\text { per perlakuan }\end{array}$} & \multirow{2}{*}{$\begin{array}{c}\text { Jumlah } \\
\text { total } \\
\text { individu }\end{array}$} \\
\hline Ordo & Spesies & $0 \%$ & $5 \%$ & $10 \%$ & $15 \%$ & \\
\hline \multirow{4}{*}{ Hymenoptera } & Polistes tenebricosus & 8 & 6 & 7 & 7 & 28 \\
\hline & Apis cerana & 9 & 7 & 12 & 5 & 33 \\
\hline & Cerratina sp. & 1 & 6 & 6 & 9 & 22 \\
\hline & Amegilla zonata & 2 & 7 & 3 & 6 & 18 \\
\hline Lepidoptera & Vanessa sp. & 14 & 12 & 13 & 6 & 45 \\
\hline Diptera & Musca domestica & 8 & 12 & 12 & 11 & 43 \\
\hline
\end{tabular}

Tabel 2. Indeks Shannon-Wienner serangga penyerbuk pada lahan tanaman strawberry yang diselingi tanaman Borreria laevicaulis di Desa Serang Kecamatan Karangreja Kabupaten Purbalingga

\begin{tabular}{cccc}
\hline Perlakuan & Jumlah Spesies & Hasil Buah & $\mathbf{H}^{\prime}$ \\
\hline $0 \%$ & 14,00 & 15,33 & 1,5620 \\
$5 \%$ & 16,67 & 15,00 & 1,7444 \\
$10 \%$ & 17,67 & 27,00 & 1,6939 \\
$15 \%$ & 18,00 & 20,00 & 1,7317 \\
\hline
\end{tabular}

Tabel 3. Tabel jumlah individu pada lahan tanaman strawberry yang diselingi tanaman Borreria laevicaulis di Desa Serang Kecamatan Karangreja Kabupaten Purbalingga

\begin{tabular}{cccccc}
\hline \multirow{2}{*}{ Perlakuan } & \multicolumn{3}{c}{ Hasil } & \multirow{2}{*}{ Jumlah } & \multirow{2}{*}{ Rataan } \\
\cline { 2 - 4 } & I & II & III & & \\
\hline $\mathbf{0 \%}$ & 11 & 14 & 17 & 42 & 14,00 a \\
$\mathbf{5 \%}$ & 15 & 13 & 22 & 50 & 16,67 a \\
$\mathbf{1 0 \%}$ & 18 & 18 & 17 & 53 & 17,67 a \\
$\mathbf{1 5 \%}$ & 11 & 17 & 26 & 54 & 18,00 a \\
\hline
\end{tabular}

Keterangan: Angka yang diikuti oleh huruf yang sama pada variabel yang sama menunjukkan tidak berbeda nyata pada BNT taraf 5\%.

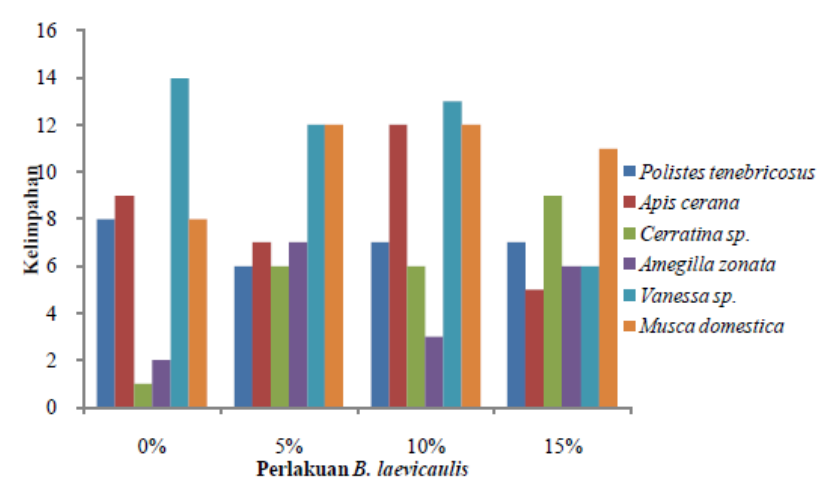

Gambar 1. Grafik jumlah spesies serangga penyerbuk pada setiap perlakuan Borreria laevicaulis.

Penanaman Borreria laevicaulis pada lahan budidaya strawberry dengan jumlah $0 \%, 5 \%, 10 \%$, dan $15 \%$ dari jumlah total individu strawberry tidak memberikan pengaruh terhadap keragaman serangga penyerbuk. 
Tabel 4. Hasil analisis ragam keragaman serangga pada lahan tanaman strawberry yang diselingi tanaman Borreria laevicaulis di Desa Serang Kecamatan Karangreja Kabupaten Purbalingga

\begin{tabular}{ccccccc}
\hline $\begin{array}{c}\text { Sumber keragaman } \\
\text { (SK) }\end{array}$ & $\begin{array}{c}\text { Derajat bebas } \\
\text { (DB) }\end{array}$ & $\begin{array}{c}\text { Jumlah kuadrat } \\
\text { (JK) }\end{array}$ & $\begin{array}{c}\text { Kuadrat tengah } \\
\text { (KT) }\end{array}$ & F & \multicolumn{2}{c}{$\mathbf{F}_{\text {tabel }}$} \\
\hline Perlakuan & $(\mathrm{t}-1)=3$ & 29,583 & 9,861 & $\mathbf{5 \%}$ & $\mathbf{1 \%}$ \\
Galat/error & $\mathrm{t}(\mathrm{r}-1)=8$ & 177,333 & 22,167 & $0,445^{* *}$ & 2,92 & 2,07 \\
\hline Total & 11 & 206,917 & & $\mathrm{KK}=27,70 \%$ SD $=3,97$ & \\
\hline
\end{tabular}

** = tidak berbeda nyata, artinya pemberian tumbuhan B. laevicaulis tidak berpengaruh terhadap keragaman serangga.

Tabel 5. Hasil analisis ragam terhadap hasil buah tanaman strawberry yang diselingi tanaman Borreria laevicaulis di Desa Serang Kecamatan Karangreja Kabupaten Purbalingga

\begin{tabular}{|c|c|c|c|c|c|c|}
\hline \multirow{2}{*}{$\begin{array}{c}\text { Sumber keragaman } \\
\text { (SK) }\end{array}$} & \multirow{2}{*}{$\begin{array}{l}\text { Derajat bebas } \\
\text { (DB) }\end{array}$} & \multirow{2}{*}{$\begin{array}{l}\text { Jumlah kuadrat } \\
\text { (JK) }\end{array}$} & \multirow{2}{*}{$\begin{array}{l}\text { Kuadrat tengah } \\
\text { (KT) }\end{array}$} & \multirow{2}{*}{$\mathbf{F}_{\text {hitung }}$} & \multicolumn{2}{|c|}{$\mathbf{F}_{\text {tabel }}$} \\
\hline & & & & & $5 \%$ & $1 \%$ \\
\hline Perlakuan & $(t-1)=3$ & 282,000 & 94,000 & & & \\
\hline Galat/error & $t(r-1)=8$ & 206,667 & 25,833 & $3,639^{*}$ & 2,92 & 4,07 \\
\hline Total & 11 & 488,667 & & $75 \%$ SD & & \\
\hline
\end{tabular}

Jumlah rata-rata serangga yang ditemukan pada masing-masing perlakuan berturut-turut yaitu 14,00 ; 16,67; 17,67; dan 18,00 (Tabel 3). Keberadaan Borreria laevicaulis di sekitar tanaman budidaya tidak menyebabkan peningkatan ataupun penurunan nilai keragaman serangga penyerbuk. Tidak adanya peningkatan keragaman dalam tiap petaknya dimungkinkan terjadi karena struktur habitat yang hampir sama, serangga penyerbuk tidak hanya mengunjungi satu bunga tetapi mengunjungi banyak bunga, dari satu bunga dalam satu petak kemudian berkunjung ke bunga lain pada lain petak. Kelimpahan tiap spesies pada tiap perlakuan memiliki jumlah yang bervariasi.

Berdasarkan Tabel 4 serangga yang ditemukan di lahan penelitian tidak dipengaruhi oleh ketersediaan B. laevicaulis. Jumlah serangga penyerbuk yang datang pada suatu bunga dapat disebabkan oleh beberapa faktor. Faktor utamanya adalah untuk mencari pakan. Pakan yang disediakan oleh bunga adalah serbuk sari dan nektar. Jika jumlah bunga pada suatu habitat melimpah maka dapat dikatakan bahwa habitat tersebut memiliki serangga penyerbuk yang beragam dan jumlahnya yang banyak. Semakin banyak bunga, kelimpahan serangga penyerbuk dapat semakin tinggi (Taki \& Kevan, 2007).

Berdasarkan hasil analisis ragam pada Tabel 5, penanaman $B$. laevicaulis mempengaruhi jumlah buah strawberry yang dihasilkan. Aplikasi B. laevicaulis terbukti dapat meningkatkan jumlah buah. Peningkatan hasil diperoleh dengan penanaman $B$. laevicaulis sebesar 10\%, sedangkan 5\% dan 15\% B. laevicaulis tidak meningkatkan hasil tanaman strawberry. Perlakuan kontrol ( $0 \%$ B. laevicaulis) didapat 15,33 buah strawberry per petak, tidak berbeda nyata dengan hasil pada perlakuan $5 \% B$. laevicaulis. Hal ini menunjukkan bahwa pemberian $5 \%$ B. laevicaulis pada budidaya strawberry tidak membantu meningkatkan hasil.

Hasil strawberry tertinggi diperoleh pada peralakuan $10 \%$ B. laevicaulis pada lahan budidaya dengan nilai rata-rata hasil sebesar 27 buah per petak. Jumlah rata-rata buah strawberry per petak dengan perlakuan B. laevicaulis $15 \%$ yaitu 20 buah. Jumlah ini lebih rendah dibandingkan dengan hasil strawberry dengan pengkayaan B. laevicaulis sebesar 10\% (Tabel 3). Perlakuan $10 \%$ B. laevicaulis menjadikan produksi strawberry meningkat sebesar 76,12\% dibandingkan hasil buah pada perlakuan kontrol. Jumlah $B$. laevicaulis pada perlakuan $10 \%$ memberikan hasil buah yang paling baik dan paling optimal dibandingkan dengan perlakuan lain. Pengamatan terhadap jumlah buah menunjukkan bahwa perlakuan yang memberikan peningkatan hasil yang paling tinggi adalah perlakuan 10\% B. Laevicaulis (Tabel 6 dan Gambar 2). Dibandingkan dengan perlakuan 10\% $B$. laevicaulis, penanaman $B$. laevicaulis yang lebih besar dari persentase tersebut tidak akan memberikan peningkatan hasil. Semakin banyak $B$. laevicaulis yang ditanam akan mengganggu ekologi tanaman strawberry, diduga menjadi kompetitor hara dan lingkungan tumbuh bagi tanaman budidaya.

Tabel 6. Tabel hasil buah pada lahan tanaman strawberry yang diselingi tanaman Borreria laevicaulis di Desa Serang Kecamatan Karangreja Kabupaten Purbalingga

\begin{tabular}{cccccc}
\hline \multirow{2}{*}{ Perlakuan } & \multicolumn{3}{c}{ Hasil } & \multirow{2}{*}{ Jumlah } & \multirow{2}{*}{ Rataan } \\
\cline { 2 - 4 } & I & II & III & & \\
\hline $\mathbf{0 \%}$ & 10 & 11 & 25 & 46 & $15,33 \mathrm{a}$ \\
$\mathbf{5 \%}$ & 10 & 17 & 18 & 45 & $15,00 \mathrm{a}$ \\
$\mathbf{1 0 \%}$ & 30 & 23 & 28 & 81 & $27,00 \mathrm{c}$ \\
$\mathbf{1 5 \%}$ & 21 & 19 & 20 & 60 & $20,00 \mathrm{~b}$ \\
\hline
\end{tabular}

Keterangan: Angka yang diikuti oleh huruf yang sama pada variabel yang sama menunjukkan tidak berbeda nyata pada BNT taraf 5\%.

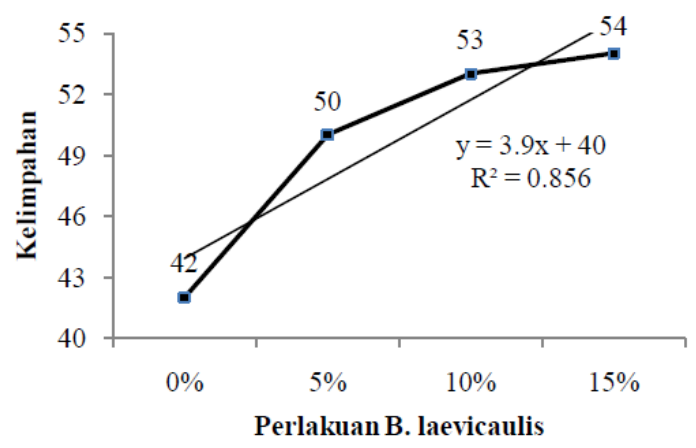

Gambar 2. Grafik Kelimpahan Serangga Penyerbuk 


\section{KESIMPULAN DAN SARAN}

Penanaman Borreria laevicaulis pada lahan tanaman strawberry tidak berpengaruh terhadap jumlah spesies serangga penyerbuk yang yang mengunjungi tanaman strawberry. Penanaman B. laevicaulis mempengaruhi jumlah buah strawberry yang dihasilkan. Peningkatan hasil diperoleh dengan penanaman B. laevicaulis sebesar $10 \%$, sedangkan $5 \%$ dan $15 \%$ B. laevicaulis tidak meningkatkan hasil tanaman strawberry. Perlakuan $10 \%$ B. laevicaulis meningkatkan produksi strawberry paling optimal yaitu sebesar 76,12\%.

Berdasarkan penelitian yang telah dilakukan di Desa Serang Kecamatan Karangreja Kabupaten Purbalingga, upaya untuk meningkatkan produksi strawberry secara alami dapat digunakan dengan pengkayaan tumbuhan $B$. laevicaulis sebagai sarana untuk meningkatkan produksi buah strawberry yang dihasilkan.

\section{DAFTAR REFERENSI}

Abrol DP. 1992. Energetics of Nectar Production in Some Strawberry Cultivars as a Predictor of Floral Choice by Honeybee. Journal Bio Science. 17(1).

Aizen SA, Garibaldi SA, Cunningham A, Klein A. 2009. How much does agriculture depend on pollination. Lesson from long-term trends in crop production. Annals of Botany. 103:1579-1588.

Albano S, Salvado E, Borges PAV, Mexia A. 2009. Floral visitors, their frequency, activity rate and index of visitation rate in the strawberry fields of Ribatejo, Portugal: selection of potential pollinators. Part 1. advertised. Horticultural. Science. 23:238245.

Brosi BJ, Armswoth PR, Daily GC. 2008. Optimal design of agricultural landscapes for pollination services. Conservation Letters. 1:27-36.

Cardenans J, Reyes WE, Doll JD. 1972. Tropical weeds. Vol 1 F Parado (ed). Bogota: ICA-IPPC. 341.p.

Corlett RT. 2004. Flower visitors and pollination in the oriental (Indomalayan) region, Hong Kong University, China. Bioloy Review. 7:497-532.

Erniwati M, Amir, Kahono S. 2005. Aktifitas Kunjungan Beberapa Jenis Lebah Pada Bunga Apel dan Jeruk Di Jawa Timur. Laporan Teknik 2005. Pusat Penelitian Biologi-LIPI. 799-805.
Erviana SI. 2011. Pembuatan Manisan Stroberi (Fragaria sp). Bogor: IPB.

Faheem M, Aslam M, Razaq M. 2004. Pollination ecology with special reference to insects a riview. Journal of Research Science. 5:395-409.

Fontaine C, Thebault E, Dajoz I. 2009. Are insect pollinators more generalist than insects herbivores. Proceeding the Royal of Society. 276:3027-3033.

Free JB. 1993. Insects Pollination of Crops. Second Edition. Academic Press. 684 pp.

Hodgson J, Atte, Miolanen, Wintle BA, Thomas CD. 2011. Habitat area, quality and connectivity: striking the balance for efficient conservation. Journal of Applied Ecology. 48:148-152.

Hoehn P, Tscharntke T, Tylianakis JM, Dewenter IS. 2008. Funcional group diversity of bee pollinators increases crop yield. Proceeding of the Royal Society B. 275:2283-2291.

Holzschuh A, Steffan-Dewenter I, Tschranke IIS. 2008. Agricultural landscapes with organic crops support higher pollinator diversity. Oikos. 117:354-361.

Magurran AE. 1988. Ecological diversity and its measurement. Princeton: Princeton University Press.

Momose K, Yumoto T, Nagamitsu T, Kato M, Nagamasu H, Sakai OS. 1998. Characteritic of the plant-pollinator community in a lowland dipterocarp forest. American Journal of Botany. 85:1477-1501.

Mussen, E. 2001. Yellow jackets and other sosial wasps. Agricultur and Natural Resources. 17:342-350.

Roselino AC, Santos SB, Hrncir M, Bego LR. 2009. Differences between the quality of strawberries (Fragaria $\mathrm{x}$ ananassa) pollinated by the stingless bees Scaptotrigona depilis and Nannotrigona testaceicornis. Genetics and Molecular Research. 8:539-545.

Singh MM. 2008 Foraging behaviour of the Himalayan honeybee (Apis cerana F.) on flowers of Fagopyrum esculentum M. and its impact an grain quality and yield. Ecoprint. 15:37-46.

Taki H, Kevan PG. 2007. Does habitat loss affect the communities of plants and insects equally in plant-pollinator interaction preliminary findings. Biodiversity Conservation. 16:3147-3161.

Widhiono I, Trisucianto, 2010. Analisis populasi lebah madu (Apis cerana dan Trigona sp.) terhadap produksi buah strawberry [Laporan Penelitian]. Purwokerto: Fakultas Biologi, Universitas Jenderal Soedirman.

Widhiono I, Sudiana, Trisucianto. 2011. Keragaman tumbuhan berbunga dan erangga penyerbuk pada lahan di sekitar lahan pertanian di lereng selatan gunung slamet [Laporan Penelitian]. Purwokerto: Fakultas Biologi, Universitas Jenderal Soedirman. 